\title{
Extensional Scientific Realism vs. Intensional Scientific Realism
}

\begin{abstract}
Extensional scientific realism is the view that each believable scientific theory is supported by the unique first-order evidence for it and that if we want to believe that it is true, we should rely on its unique first-order evidence. In contrast, intensional scientific realism is the view that all believable scientific theories have a common feature and that we should rely on it to determine whether a theory is believable or not. Fitzpatrick argues that extensional realism is immune, while intensional realism is not, to the pessimistic induction. I reply that if extensional realism overcomes the pessimistic induction at all, that is because it implicitly relies on the theoretical resource of intensional realism. I also argue that extensional realism, by nature, cannot embed a criterion for distinguishing between believable and unbelievable theories.
\end{abstract}

Seungbae Park

nature@unist.ac.kr

Ulsan National Institute of Science and Technology

Park, Seungbae (2016). "Extensional Scientific Realism vs. Intensional Scientific Realism", Studies in History and Philosophy of Science 59: 46-52.

Acknowledgement: I thank Simon Fitzpatrick, Craig Callender, anonymous referees, and the editors of this journal for useful comments. This work was completed while I was visiting Department of Philosophy, University of California - San Diego in 2015. I thank Craig Callender, the department chair, for his hospitality.

\section{Keywords}

Intensional Realism, No-Miracles Argument, Extensional Realism, Pessimistic Induction, Scientific Realism

\section{Introduction}

The no-miracles argument (Putnam, 1975; Psillos, 1999) and the pessimistic induction (Poincaré, 1905/1952: 160; Laudan 1977: 126; Putnam, 1978: 250; Stanford, 2006) are regarded as the best arguments for scientific realism and antirealism, respectively. The nomiracles argument holds that the success of scientific theories would be miracles if they are (completely) false. The realist hypothesis that they are (approximately) true provides the best explanation of their success. The pessimistic induction, on the other hand, holds that successful past theories, such as the phlogiston theory and the caloric theory, turned out to be (completely) false, so successful present theories, such as the oxygen theory and the kinetic theory, will also turn out to be (completely) false. These rough formulations of the nomiracles argument and the pessimistic induction do not accurately represent the sophisticated positions defended by philosophers in the literature, but they are good enough to serve the purpose of this paper.

This paper focuses on a certain trend in the literature concerning the no-miracles argument and the pessimistic induction. A growing number of philosophers (Lipton, 2001; Achinstein, 2002; Enfield, 2008; Roush, 2010; Fitzpatrick, 2013) argue that we should rely on scientists' arguments for scientific theories as opposed to the no-miracles argument to arrive at realism. This view has not yet received its due attention in the literature, although it 
contains a valuable insight on how we should evaluate scientific theories, as will become clear in this paper.

This paper is structured as follows. In Section 2, I clarify the key terms: 'extensional scientific realism' and 'intensional scientific realism.' In Section 3, I argue that the nomiracles argument is reducible to a collection of all the scientific arguments for successful theories, so it does not provide additional support for scientific theories. In Section 4, I argue that the mere difference between the first-order evidence for present theories and that for past theories does not make present theories immune to the pessimistic induction. What really makes present theories immune to it is that the first-order evidence for them is more powerful than that for past theories. In Section 5, I reply to a possible objection that it is problematic to develop a new position that gets around the pessimistic induction because the pessimistic induction has already been conquered.

\section{Extensional vs. Intensional}

We teach our undergraduates that there are basically two ways to define a word like 'bachelor.' They are extensional and intensional definitions. An extensional definition specifies all the objects that a term can be correctly applied to. So 'bachelor' is extensionally defined as Tom, John, Eric, and so on. By contrast, an intensional definition specifies all the properties that the objects have in common. So 'bachelor' is intensionally defined as an unmarried adult male. It is much more cumbersome to give an extensional definition than to give an intensional definition. An intensional definition saves us from the pain of enumerating all the relevant objects in the world. The distinction between extensional and intensional definitions will be utilized in this section to cast light on scientific realism.

How can we go about picking out believable theories from science? Just as there are two ways to pick out bachelors, so there are two ways to pick out believable theories. The first method is to enumerate them. So believable theories are the oxygen theory, the kinetic theory, the general theory of relativity, evolutionary theory, and so forth. If challenged to justify the choice of these theories, we can specify the first-order evidence for each of them. The first-order evidence is the evidence that scientists provide to justify their theories. This method to choose believable theories leads to the view that I call 'extensional scientific realism' ('extensional realism,' for short). It asserts that we should enumerate believable theories and that we should rely on the unique first-order evidence for each theory to determine whether it is believable or not. On this account, the unit of evaluation is not a set of theories but an individual theory.

The second method to pick out believable theories from science is to use their common property. Hilary Putnam (1975), for example, suggests that success is the common property of all believable theories. ${ }^{1}$ If challenged to justify the choice of the property, he would say that a false theory cannot have the property. This method to choose believable theories leads to the view that I call 'intensional scientific realism' ('intensional realism,' for short). It asserts that we should use a common property to pick out believable theories and cite the common property as the evidence for the choice of the theories. On this account, the unit of evaluation is not an individual theory but a set of theories. Intensional realists believe, for example, that successful theories are true on the grounds that false theories cannot be successful. Thus, intensional realism is built into the no-miracles argument.

Suppose that extensional realists have enumerated all believable theories in consideration of how strong scientists' arguments are. Would this show that all believable

\footnotetext{
${ }^{1}$ Different intensional realists put forward different common properties. Jarrett Leplin (1997) and Juha Saatsi (2009: 358) propose that believable theories make novel predictions. Seungbae Park (2011a) proposes that believable theories are successful ones that cohere with each other.
} 
theories have a common property? P. D. Magnus and Craig Callender (2004) would answer no to this question. They claim that reflecting "on the vast complexities of various historical episodes in science, there is no reason to think that the general assumptions one finds will be at all simple, natural, or even non-disjunctive" (2004: 335). Therefore, it is one thing that all believable theories are enumerated, yet it is another that a common property emerges from the collection of all believable theories. In any event, intensional realists have, while extensional realists do not, the burden to specify the common property.

A terminological issue needs to be addressed. How does the distinction between extensional realism and intensional realism relate to Magnus and Callender's (2004) distinction between retail and wholesale arguments and to Simon Fitzpatrick's (2013) distinction between local and global strategies? Are the three distinctions different distinctions or the same distinction in different guises?

Magnus and Callender say that retail arguments are "arguments about specific kinds of things such as neutrinos" whereas wholesale arguments are "arguments about all or most of the entities posited in our best scientific theories" (2004: 321). In business, to sell goods in retail is to sell them one by one to consumers, whereas to sell wholesale goods is to sell them as a group to other businesses. As such, retailism and wholesalism in the realism debate could be taken to mean that we should evaluate scientists' arguments for the existence of theoretical entities one by one and as a group, respectively. Retailists might think, for example, that scientists' argument for the existence of neutrinos is convincing while their argument for the existence of top quarks is not. As a result, retailists might embrace realism about neutrinos while embracing antirealism about top quarks (Magnus and Callender, 2004: 333). In contrast, wholesalists evaluate general arguments, ranging over all theoretical entities of our best theories, such as the no-miracles argument, the pessimistic induction, and the problem of underdetermination. As a result, they embrace either realism or antirealism en masse concerning all theoretical entities of our best theories, i.e., they believe either that all of them exist or that neither of them exists.

The retail/wholesale distinction differs somewhat from the extensional/intensional distinction. Retailists and wholesalists may disagree as to which theoretical entities we are justified in believing and not justified in believing. For example, retailists might believe that neutrinos exist but that top quarks do not, whereas wholesalists might believe that both neutrinos and top quarks exist or that neither of them does. By contrast, extensionalists and intensionalists agree about which theories are warranted and which theories are not, just as they agree on who are bachelors and who are not. They agree, for example, that the oxygen theory, the kinetic theory, and evolutionary theory are warranted, just as they agree that John, Tom, Eric, and so on are bachelors. ${ }^{2}$

Fitzpatrick's local/global distinction does not differ from the extensional/intensional distinction. 'Extensional realism,' however, better captures what Fitzpatrick has in mind. Local realism can be interpreted as the view that all the theories in a particular field of science are warranted, but all the theories in another field of science are not, given that Samuel Ruhmkorff (2014: 410) distinguishes between the local pessimistic induction and the global pessimistic induction. Local pessimists are pessimistic about all the theories in a particular field of science, but not about other theories in other fields of science. In contrast, global pessimists are pessimistic about all the theories in all fields of science. Extensional realists, however, reject the suggestion that all the theories in a particular field of science can be evaluated as a whole. They believe that different theories, even if they belong to the same field of science, say, physics, should be evaluated on a case-by-case basis, the reason being

\footnotetext{
${ }^{2}$ My interpretation of the retail/wholesale distinction is endorsed by Callender (Personal Communication).
} 
that they are supported by different sets of first-order evidence. Thus, 'extensional realism' better captures than 'local realism' the view that the unit of evaluation is not a set of theories but an individual theory.

How does the extensional/intensional distinction relate to the first-order/second-order distinction? The first-order evidence for scientific theories is the evidence that scientists provide to justify them, whereas the second-order evidence for scientific theories is the evidence that allegedly arises when philosophers reflect on the first-order evidence. Both extensional realism and intensional realism are committed to the existence of the first-order evidence, but not to the existence of the second-order evidence. As we will see in the next section, Stathis Psillos (2011) argues that the no-miracles argument provides the second-order evidence for scientific theories. I will argue, however, that the alleged second-order evidence is reducible to the first-order evidence and that the no-miracles argument does not provide the second-order evidence for scientific theories.

An objection against extensional realism arises. Extensional realists would believe such theories as the oxygen theory and the kinetic theory, but not such theories as the phlogiston theory and the caloric theory. But how do they go about distinguishing between believable and unbelievable theories? It is ad hoc to suggest that believable theories are present theories and unbelievable theories are past theories. There should be a criterion for differentiating between believable and unbelievable theories independently of whether they are past or present theories. Extensional realists, however, cannot provide such a criterion because that goes against the spirit of extensional realism. They can only specify the first-order evidence for each theory, and then hope that we make correct intuitive judgments about which theories are believable and which theories are unbelievable.

Some philosophers, however, would not be happy with the absence of the criterion for distinguishing between believable and unbelievable theories. Consider P. Kyle Stanford's (2006, 2009) critical response to selective realism. Philip Kitcher (1993: 140-149) and Psillos (1999: Chapters 5 and 6) observe that the working posits of past theories are retained in present theories, although the idle posits of past theories were discarded. On the basis of this observation, Psillos (1999: 113) concludes that past theories are not completely false but approximately true. Stanford replies that realists need to offer a criterion for distinguishing between working and idle posits. In the absence of the criterion, we cannot recognize the working and idle posits of present theories, although we can recognize the working and idle posits of past theories in retrospect. Imagine that Kitcher and Psillos say to Stanford that once we identify the various parts of present theories, we can make correct intuitive judgments about which parts are working posits and which parts are idle posits, so we do not need a criterion for distinguishing between working and idle posits. Stanford would not be satisfied with such a response, insisting that we need a criterion for distinguishing between working and idle posits. The same point applies to extensional realists' mere specifications of the firstorder evidence for scientific theories.

The quest for a criterion is a prevalent phenomenon in philosophical enterprises. Normative ethicists pursue the criterion for distinguishing between moral and immoral acts. Utilitarianism and Kantianism provide, respectively, the maximization of happiness and the will that your maxim should become a universal law as criteria for differentiating between moral and immoral actions. Epistemologists pursue the criterion for distinguishing between justified and unjustified beliefs. Foundationalism, coherentism, and reliabilism provide, respectively, well-foundedness, coherence, and reliability of cognitive process as criteria for differentiating between justified and unjustified beliefs. Intensional realism is along this line philosophical tradition. 
Extensional realists, however, would retort that the absence of the criterion is the very advantage of extensional realism, arguing that Stanford's criticism against selective realism does not apply to extensional realism since extensional realism does not require the distinction between stable and unstable constituents in the first place. Intensional realists would reply that the absence of the criterion is the very disadvantage of extensional realism, arguing that if extensional realists are right, it is not clear why ethicists and epistemologists strive for criteria in their fields of philosophy. Extensional and intensional realists have reached a stalemate. The dispute between them leads to the fundamental question of what the aims of philosophy are.

\section{The Reductive Interpretation of the No-Miracles Argument}

Psillos, a leading defender of the no-miracles argument, does not deny that scientific theories receive support from the first-order evidence for them. What he denies is that the first-order evidence is the only source of support for scientific theories. According to him, the nomiracles argument provides additional support for scientific theories:

It would be folly, however, to think that considerations concerning the second-order evidence should be totally wiped out - or worse, that these considerations to which working scientists are blind. These are meta-theoretical or philosophical considerations that do get into the evidential balance sheet nonetheless. (Psillos, 2011: 188)

On Psillos's account, the no-miracles argument plays a justificatory role for all successful theories in science. All successful theories are more probable thanks to this overarching philosophical argument for them.

In contrast, extensional and intensional realists claim that the no-miracles argument does not provide additional support for it. Peter Lipton and Patrick Enfield write as follows:

[A]t the end of the day, the only evidence for the truth of scientific theories is the evidence that scientists' use, and the only positive arguments for scientific realism are the arguments that scientists make. (Lipton, 2001: 353)

The only sensible way to find out whether a scientific claim is true is by looking at the original scientific evidence previously offered by scientists. We can, of course, find scientific evidence wanting. But when we believe scientific claims to be true, it is because of this evidence, not on the basis of some kind of abductive argument for realism as an overarching empirical hypothesis. (Enfield, 2008: 891)

On this account, only scientific arguments justify scientific theories, and hence philosophers of science are not in the business of justifying scientific theories but instead in the business of taking attitudes toward scientific theories in the realism debate.

Regarding this issue, I disagree with Psillos and agree with Lipton and Enfield. My agreement with Lipton and Enfield is predicated on my interpretation of scientific realism and the no-miracles argument. In my view, scientific realism, the position that successful theories are true, is merely a shorthand for the claims that evolutionary theory, the general theory of relativity, the kinetic theory, and so forth are true, just as the claim that a bachelor is unmarried is a shorthand for the claims that Tom, John, Eric, and so on are unmarried. Also, the no-miracles argument is merely a shorthand for all the arguments that scientists provided to support their successful theories. The no-miracles argument claims that some theories are successful because they are true and that their success would be miracles if they were false. This argument is merely a succinct summary of the following list of scientific arguments: 


\section{The List of Scientific Arguments}

- A human embryo develops a gill because human beings have evolved from fish. It would be a miracle that a human embryo develops a gill and yet human beings have not evolved from fish. (Evolutionary Theory)

- Light bends near the sun because spacetime is curved. It would be a miracle that light bends near the sun and yet spacetime is not curved. (The General Theory of Relativity)

- Two pieces of cold metal get hot when rubbed at high speed because heat is nothing but the motion of molecules. It would be a miracle that they get hot and yet the temperature is not the mean kinetic energy of molecules. (The Kinetic Theory)

- etc.

This list of scientific arguments should be expanded to include all contents of a believable theory, all contents of the first-order evidence for it, all believable theories, and all first-order evidence for them in the science literature. The list can be completed only after extremely grueling work. We can, however, avoid this grueling work thanks to the no-miracles argument. It tells us in a few sentences which theories are believable and why they are believable.

Of course, scientists do not use the word 'miracle' when they formulate their arguments. Their arguments, however, can be reformulated as invoking the notion of miracle. For example, Charles Darwin says:

And we can clearly understand these analogies, if species have once existed as varieties, and have thus originated: whereas, these analogies are utterly inexplicable if each species has been independently created. (Darwin 1859/1993: 146)

Darwin's argument that analogies can be explained by evolutionary theory, but not by creationism, can be recast as saying that the existence of analogies would be a miracle if different species were independently created, and hence different species have evolved from the same ancestor. It follows that Darwin's argument is a particular no-miracle argument for evolutionary theory and that Putnam's no-miracles argument is nothing but a collection of such scientific arguments in all fields of science.

One might object that Darwin's argument above concerns the explanatory success of evolutionary theory, but some scientific arguments rely on the predictive success of scientific theories. ${ }^{3}$ For example, before the $20^{\text {th }}$ century, scientists predicted the bending of starlight near the sun with the use of classical mechanics, but the value of light bending that they calculated was only half the correct value. Einstein calculated the correct value with the use of the general theory of relativity in the early $20^{\text {th }}$ century (Will, 2014). After confirming Einstein's prediction, scientists concluded that spacetime is curved near a massive object. So Putnam's no-miracles argument is not reducible to a collection of scientific arguments for successful theories.

My response is to highlight that Putnam's no-miracles argument is not only about the explanatory success but also about the predictive success of theories and that the physicists' argument for the general theory of relativity can also be reconstructed as invoking the notion

${ }^{3}$ I thank a referee for this sharp criticism. 
of miracle. The reconstructed argument states that it would be a miracle for light to bend near the sun as the general theory of relativity predicts, and yet spacetime is not curved near a massive object, and hence spacetime is curved near a massive object. Therefore, the fact that some scientists' arguments rely on predictive success does not undermine my suggestion that Putnam's no-miracles argument is reducible to a collection of scientists' arguments for scientific theories.

My contention that scientists' arguments can be reformulated as invoking the notion of miracle whether concerning explanations or predictions captures Psillos's intuition cited above that it would be folly to think that working scientists are blind to Putnam's no-miracles argument (2011: 188). On Psillos's account, scientists are not blind to Putnam's no-miracles argument whether they advance explanatory or predictive arguments. His contention goes well with my contention that scientists advance a particular no-miracle argument whether it relies on the explanatory success or the predictive success of a theory.

My preceding interpretation of the no-miracles argument clashes with Psillos's contention that the no-miracles argument provides an additional justification for all successful theories. On my interpretation, the no-miracles argument is reducible to the collection of scientific arguments for successful theories, just as a collection of unmarried adult males is reducible to the collection of John, Tom, Eric, and so on. It follows that the support that the no-miracles argument provides for scientific realism is also reducible to the support that scientific arguments provide for successful theories. Hence, the no-miracles argument does not provide any additional support for successful theories.

This corollary of my interpretation can be clarified with the use of an analogy. If the government has collected due taxes from John, Tom, Eric, and so forth, then it has collected all the due taxes from bachelors. It is a mistake for the government to expect additional taxes from unmarried adult males. To put schematically, if $\mathrm{X}$ is reducible to $\mathrm{Y}$, and if $\mathrm{Y}$ does not have a certain property, $X$ does not have that property either. It is a mistake to think that $X$ has that property although $\mathrm{Y}$ does not. Thus, it is a mistake to think that the no-miracles argument has evidential power that the collection of all scientific arguments does not have.

\section{Against Mere Difference}

\subsection{Alleged Advantage}

Fitzpatrick (2013) claims that extensional realism has an advantage over intensional realism inherent in the no-miracles argument. The advantage is that while intensional realism is subject to the pessimistic induction, extensional realism is not. Intensional realism claims at a general level that successful theories are true. Pessimists object equally at the general level that the history of science is the wasteland of successful and yet false theories, so successful theories, both past and present, are false:

The NMA [no-miracles argument] provides easy grist for the mill of the historically motivated pessimist because it asserts a completely general connection between empirical success and approximate truth. (Fitzpatrick, 2013: 144)

The idea is that the no-miracles argument uses the property, success, to pick out believable theories from current science. A problem is that this property is possessed not only by our best present theories but also by our best past theories. So the predicate 'success' ends up picking out unbelievable theories as well as believable ones, opening a door to the pessimistic induction.

In contrast, extensional realism is insusceptible to the pessimistic induction because it does not use the common property of past and present theories to pick out believable present 
theories. It rather uses the distinctive first-order evidence for present theories. Sherrilyn Roush writes as follows:

Since our evidence set is relevantly different from our predecessors', it remains to be shown why their failure is a reason to believe in ours. (Roush, 2010: 34)

For example, the first-order evidence for the kinetic theory is different from that for the caloric theory because the former includes, but the latter does not, the observational evidence that two pieces of cold metal become hot when rubbed at high speed. Extensional realists say that the kinetic theory is true not on the grounds that it is successful but on the grounds that it is supported by the observational evidence, such as the observational evidence of the two pieces of cold metal. This first-order argument for the kinetic theory is not undermined by the historical fact that the caloric theory turned out to be false, for the two theories are supported by different sets of first-order evidence. In short, extensional realists avert the pessimistic induction by driving a wedge between past and present theories.

In the literature, however, intensional realists also drive a wedge between past and present theories. Leplin (1997: 141), Gerald Doppelt, (2007: 111; 2014), Peter Godfrey-Smith (2008: 143), Juha Saatsi (2009: 358), Michael Devitt (2011: 292), Samuel Ruhmkorff (2011: 878), Park (2011b), Ludwig Fahrbach (2011a; 2011b), and Moti Mizrahi (2013) argue that present theories are more successful than past theories, i.e., the present first-order evidence is more powerful than the past first-order evidence. So from the fact that past theories were discarded, it does not follow that present theories will also be discarded. Their observation of the general difference between past and present theories is intended to protect present theories from the pessimistic induction. Consequently, it is problematic to say that extensional realism does better than intensional realism vis-à-vis the pessimistic induction.

\subsection{Better Evidence}

I argued above that intensional realists have a theoretical resource to diffuse the pessimistic induction. In this section, I argue that extensional realists cannot overcome the pessimistic induction, unless they rely on the theoretical resource that intensional realists rely on.

How would pessimists tackle extensional realism? They would invite extensional realists to imagine, for example, that Joseph Black was confident that the caloric theory was established by its first-order evidence. ${ }^{4}$ In retrospect, however, we can see that his confidence was not well-grounded. Similarly, even if we are confident now that the kinetic theory is established by its first-order evidence, our confidence is not well-grounded. It follows that extensional realism falls prey to the pessimistic induction.

Fitzpatrick (2013: 145), however, anticipates the foregoing objection to extensional realism. His response is to fall back on extensional realism. He appeals to Roush's observation that the first-order evidence for present theories is different from the first-order evidence for past theories:

But, as Roush (2010) has argued, in an insightful piece on the PI [pessimistic induction], that kind of induction obscures the fact that the content of the evidence we have for current theoretical claims is quite different to that which supported now abandoned claims of previous scientists. (Fitzpatrick, 2013: 145)

\footnotetext{
${ }^{4}$ See Psillos (1999, Chapter 6), Hasok Chang (2003), and Stanford (2006, Chapter 7) for the set of the firstorder evidence for the caloric theory.
} 
In my view, pessimists would admit that the first-order evidence for present theories is different from the first-order evidence for past theories, but would insist that the unfortunate fate of past theories will befall present theories, arguing that the mere difference of the firstorder evidence does not mean that past and present theories have different fates. So pessimists and extensional realists have reached a stalemate.

The stalemate can be broken in pessimists' favor with the following consideration. Suppose that we have two theories: $T_{1}$ and $T_{2}$. The first-order evidence for $T_{1}$ is different from that for $T_{2}$. But the degree to which $T_{1}$ is supported by its first-order evidence is exactly the same as the degree to which $\mathrm{T}_{2}$ is supported by its first-order evidence. Unfortunately, $\mathrm{T}_{1}$ turned out to be false. In such circumstances, the proponents of $\mathrm{T}_{2}$ would have to worry that $\mathrm{T}_{2}$ might be false too. They cannot take comfort from the fact that the first-order evidence for $\mathrm{T}_{2}$ is different from that for $\mathrm{T}_{1}$. It is wrong to be optimistic about $\mathrm{T}_{2}$.

Let me use an example to illustrate the preceding objection. There is a cognitive disorder called prosopagnosia. A patient suffering from prosopagnosia has a problem in recognizing faces. He can recognize each part of a face, but cannot tell whose face it is. He cannot even recognize his family member's face. But he can recognize other objects, such as hands and trees. Cognitive scientists hypothesize that we have a module called the face recognition system. The face recognition system specializes in processing the information about faces. Prosopagnosia occurs when the face recognition system breaks down. Imagine that a patient with prosopagnosia made ten judgments about ten faces and that all of them were false. He presently makes a judgment about a new face. We would think that his judgment about the new face is likely to be false. After all, all of his ten similar previous judgments were false. It is inapposite to say that it is up for grab whether the present judgment is true or false on the grounds that the present perceptual evidence is different from the past perceptual evidence.

The prosopagnosia example is not intended to saddle extensional realism with the controversial epistemological view that perceptual evidence is all the evidence for a scientific theory. It is rather intended to show that the mere difference between the scientific arguments for present theories and those for past theories is not enough to overcome the pessimistic induction. Extensional realists can happily agree with Carl Hempel (1966: 38-39) that a scientific theory receives not only observational support but also theoretical support, i.e., it receives support not only from observational evidence but also from other scientific theories, and with Park (2011a: 27-28) that theoretical support is not reducible to observational support. Extensional realists acknowledge the existence of theoretical support in science, given that theoretical support is not second-order support for a theory. It exists independently of some philosophers' attempts to justify scientific theories, and existed before Hempel observed it and created the name 'theoretical support' for it.

The prosopagnosia example is not intended to justify the pessimistic induction either. It is rather intended to illustrate that even if the first-order evidence for $T_{1}$ and that for $T_{2}$ are different, $\mathrm{T}_{1}$ and $\mathrm{T}_{2}$ might be of the same low degree of trustworthiness. This point undermines Fitzpatrick's claim that since the first-order evidence for past theories is different from the first-order evidence for present theories, it is one thing that past theories are not trustworthy, and it is another that present theories are not trustworthy. Thus, the mere difference of the first-order evidence cannot do the job of protecting present theories from the pessimistic induction.

Roush, however, anticipates my preceding objection. She says that "we could easily churn out different evidence in each round of research, but maintain the same miserable level of unreliability, for example because we use the same sorry ways of gathering evidence" (2010: 47). She spends an entire section (2010: 46-52) responding to the objection, wrapping 
up her discussion by saying that the "bottom line for our argument here is that these sophisticated methods are used today and were not used by our predecessors in earlier centuries, method is relevant to reliability - as we have shown by showing that some later ones are more reliable than some or all earlier ones" (2010: 52).

Note, however, that Roush's sentence implies that present science uses better methods than past science, which in turn implies that present evidence is better than past evidence. Moreover, in the introduction of her paper, Roush says, "the content of our evidence propositions and evidence sets is different from the content of theirs; at the very least there is more of it" (Roush, 2010: 34). Her sentence implies that the set of present evidence is larger than that of past evidence. In a nutshell, Roush relies on the observation, as intensional realists do, that present theories are better than past theories in order to diffuse the pessimistic induction.

Peter Achinstein (2002) and Fitzpatrick (2013) rely on the case study of Perrin's determination of Avogadro's number to make a case for extensional realism. I must point out, however, that the first-order evidence for Avogadro's number is much more powerful than the first-order evidence for any past theory. Several independent methods, including those involving the electromagnetic theory and the kinetic theory, were used to calculate Avogadro's number. All of them resulted in the same conclusion that the number of molecules in one mole of a substance is approximately $6 \times 10^{23}$. Given that the first-order evidence for the electromagnetic theory and that for the kinetic theory supported Avogadro's number, Avogadro's number was confirmed more highly than any past theory. Thus, Achinstein and Fitzpatrick's case for realism implicitly depends on the fact that the first-order evidence for Avogadro's number is more powerful than that for any past theory.

A case study that would avoid the charge that extensional realists implicitly rely on the theoretical resource that intensional realists rely on would be about a past theory and a present theory which differ in terms of the contents of the first-order evidence, but not in terms of the strengths of the first-order evidence. Fitzpatrick's view would undoubtedly be established, if the present theory and the past theory are on different epistemic boats despite the fact that the first-order evidence for the present theory is not more powerful than that for the past theory.

It would, however, be difficult to offer such a past theory and a present theory. As the prosopagnosia example illustrates, the mere difference between the first-order evidence for $T_{1}$ and that for $\mathrm{T}_{2}$ does not mean that they are on different epistemic boats. Furthermore, as Leplin (1997: 144) and Alexander Bird (2007) point out, present theories are the very products of scientists' efforts to improve upon past theories. For example, the kinetic theory was proposed in response to the problems that afflicted the caloric theory. For this reason, it is infeasible that extensional realists can come up with a past theory and a present theory which are similar in terms of the strength of the evidence but dissimilar in terms of the content of the evidence.

Fitzpatrick might argue that it is wrong to project the fate of a present theory from that of a past theory because the context in which a present theory is placed is different from that in which a past theory was placed, i.e., because the background beliefs of a present theory are different from those of a past theory. After all, Fitzpatrick approvingly cites Achinstein's contention that the epistemic force of Perrin's argument for Avogadro's number "can only be appreciated within the context of a rich network of background beliefs" (Fitzpatrick, 2013: 146). On this account, the mere difference of past and present contexts makes the pessimistic induction fallacious.

I insist, however, that if the extensional strategy works at all, that is because it relies on the fact that present theories are better than past theories. This time, however, I use not the 
prosopagnosia example but the following example of inferences from (1) to (2) and from (1) to $(3)$ :

(1) The context of the germ theory is different from that of the miasma theory.

(2) Even if the miasma theory is unwarranted, the germ theory is warranted.

(3) Even if the miasma theory is warranted, the germ theory is unwarranted.

Extensional realists infer from (1) to (2). But what if someone infers from (1) to (3)? Why is (3) an absurd conclusion to draw from (1)? Extensional realists cannot invoke (1) to answer this question because that would beg the question. The only reasonable answer to the question is that the first-order evidence for the germ theory is better than that for the miasma theory. To use Fitzpatrick's terminology, the context of the germ theory is better than that of the miasma theory. For example, the germ theory meshes well with molecular biology, but the miasma theory did not even have a chance to mesh well with molecular biology. Such differences make the germ theory better than the miasma theory. Thus, it is not the mere difference between past and present contexts but the improvement of present contexts over past contexts that makes the pessimistic induction incorrect.

\section{Defending Extensional Realism}

I discussed above whether extensional realism better overcomes the pessimistic induction than intensional realism. It might be objected, however, that my discussion is problematic because the pessimistic induction has already been invalidated by a barrage of criticisms from realists, including selective realists. We are epistemically safe from the pessimistic induction, once we believe, as selective realists do, that only working posits of our best theories are true. The pessimistic induction is no longer a threat to realism. As such, what is the point of developing extensional realism when the pessimistic induction is already conquered?

Two replies are possible. First, the preceding objection applies not only to extensional realism but also to other philosophers' positions. As K. Brad Wray observed, realists are developing various modest forms of realism that gets around the pessimistic induction:

But given the history of science, realists need to be cautious. Those developing and defending the various modest forms of realism tacitly acknowledge this. (Wray, 2015: 70)

Saatsi, for example, has developed a position that he refers to as 'minimal realism,' arguing that minimal realism "can be maintained in the face of the historical evidence" (forthcoming). All such positions are not well-motivated, if the aforementioned objection is reasonable. What is the point of developing them when the pessimistic induction has already been conquered? Saatsi would reply that the tenability of his position is independent of whether there are other realist positions that can be maintained in the face of the pessimistic induction.

Second, recall that extensional realism and intensional realism have been developed with the view to capturing the different ways to choose believable theories from science. Extensional realism holds that we should enumerate believable theories and that the justification for the choice lies in scientists' arguments for them. By contrast, intensional realism holds that all believable theories have a common feature and that we should use this common feature to pick them out and to justify the choice of them. As far as I know, no one in the literature has explicitly addressed the issue of how we can go about choosing believable theories from science, making the distinction between the extensional way and the intensional way to do so. Such a distinction is useful or useless independently of whether the pessimistic induction is correct or incorrect. To go further, extensional realism is useful to 
realists, even if the pessimistic induction is refuted. In Section 2, I said that intensional realists have, while extensional realists do not, the burden to specify a property common to all believable theories. If Magnus and Callender are right, the burden is a heavy one. Thus, if realists choose extensional realism over intensional realism, they are freed from this burden.

\section{Conclusion}

Fitzpatrick claims that the mere difference between the first-order evidence for past theories and the first-order evidence for present theories enables us to avoid the pessimistic induction. I argued that if extensional realists overcome the pessimistic induction at all, that is because they implicitly rely on intensional realists' observation that the first-order evidence for present theories is more powerful than the first-order evidence for past theories.

I must point out, however, that it is not part of extensional realism that the mere difference between scientists' arguments for past theories and their arguments for present theories is enough to avert the pessimistic induction. Moreover, extensional realism enshrines Fitzpatrick's insights that we should evaluate scientific theories not collectively but individually and that we should rely on scientists' arguments as opposed to the no-miracles argument in order to arrive at realism.

\section{References}

Achinstein, Peter (2002). "Is There a Valid Experimental Argument for Scientific Realism?", Journal of Philosophy 99 (9): 470-495.

Bird, Alexander (2007). "What Is Scientific Progress?”, Noûs 41 (1): 64-89.

Chang, Hasok (2003). "Preservative Realism and Its Discontents: Revisiting Caloric", Philosophy of Science 70 (5): 902- 912.

Darwin, C. 1859/1993. The Origin of Species. In The Portable Darwin. Duncan Porter and Peter Graham (eds.), Paris: Penguin Books.

Devitt, Michael (2011). “Are Unconceived Alternatives a Problem for Scientific Realism?", Journal for General Philosophy of Science 42 (2): 285-293.

Doppelt, Gerald (2007). "Reconstructing Scientific Realism to Rebut the Pessimistic Metainduction", Philosophy of Science 74 (1): 96-118.

(2014). "Best Theory Scientific Realism", European Journal for Philosophy of Science 4 (2): 271-291.

Enfield, Patrick (2008). Review of P. Kyle Stanford's Exceeding Our Grasp: Science, History, and the Problem of Unconceived Alternatives, The British Journal for the Philosophy of Science 59 (4): 881-895.

Fahrbach, Ludwig (2011a). "How the Growth of Science Ends Theory Change", Synthese 180 (2): 139-155.

1283-1292.

(2011b). "Theory Change and Degrees of Success", Philosophy of Science 78 (5): 
Fitzpatrick, Simon (2013). "Doing Away with the No Miracles Argument", in V. Karakostas and D. Dieks (eds.), EPSA11 Perspectives and Foundational Problems in Philosophy of Science. The European Philosophy of Science Association Proceedings 2: 141-151. Springer International Publishing Switzerland.

Godfrey-Smith, Peter (2008). "Recurrent Transient Underdetermination and the Glass Half Full”, Philosophical Studies 137: 141-148.

Hempel, C. 1966. Philosophy of Natural Science. Englewood Cliffs, NJ: Prentice-Hall.

Kitcher, Philip (1993). The Advancement of Science: Science without Legend, Objectivity without Illusions. New York: Oxford University Press.

Laudan, Larry (1977). Progress and its Problems: Towards a Theory of Scientific Growth. California: University of California Press.

Leplin, Jarrett (1997). A Novel Defense of Scientific Realism. New York: Oxford University Press.

Lipton, Peter (2001). "Quests of a Realist" (Review Symposium on Psillos's Scientific Realism: How Science Tracks Truth), Metascience 10: 347-353.

Magnus, P. D. and Craig Callender (2004). "Realist Ennui and the Base Rate Fallacy", Philosophy of Science 71 (3): 320-338.

Mizrahi, Moti (2013). “The Pessimistic Induction: A Bad Argument Gone Too Far", Synthese 190 (15): 3209-3226.

Park, Seungbae (2011a). "Coherence of Our Best Scientific Theories", Foundations of Science 16 (1): 21-30.

(2011b). "A Confutation of the Pessimistic Induction", Journal for General Philosophy of Science 42 (1): 75-84.

Poincaré, Henri (1905/1952). Science and Hypothesis. New York: Dover.

Psillos, Stathis (1999). Scientific Realism: How Science Tracks Truth. New York: Routledge.

-------- (2011). "Making Contact with Molecules: On Perrin and Achinstein", In Gregory J. Morgan (ed.), Philosophy of Science Matters: The Philosophy of Peter Achinstein. Oxford: Oxford University Press.

Putnam, Hilary (1975). Mathematics, Matter and Method (Philosophical Papers, vo. 1), Cambridge: Cambridge University Press.

(1978). Meaning and the Moral Sciences. London: Routledge \& K. Paul. 
Roush, Sherrilyn (2010). "Optimism about the Pessimistic Induction", In New Waves in Philosophy of Science. P. D. Magnus and Jacob Bush (eds.), Basingstoke: Palgrave Macmillan.

Ruhmkorff, Samuel (2011). "Some Difficulties for the Problem of Unconceived Alternatives", Philosophy of Science 78 (5): 875-886.

--------- (2014). “Global and Local Pessimistic Meta-Inductions", International Studies in the Philosophy of Science 27 (4): 409-429.

Saatsi, Juha (2009). "Grasping at Realist Straws", Review Symposium, Metascience 18 (3): $355-362$.

(forthcoming). "Historical Inductions, Old and New", Synthese.

Stanford, P. Kyle (2006). Exceeding Our Grasp: Science, History, and the Problem of Unconceived Alternatives. Oxford: Oxford University Press.

--------- (2009). “Grasping at Realist Straws”, Review Symposium, Metascience 18 (3): 379390.

Will, Clifford (2014). "The Confrontation between General Relativity and Experiment", Living Rv. Relativity 17 (4) URL (cited on April 29, 2016), http://www.livingreviews.org/lrr2014-4.

Wray, K. Brad (2015). "Pessimistic Inductions: Four Varieties", International Studies in the Philosophy of Science 29 (1): 61-73. 